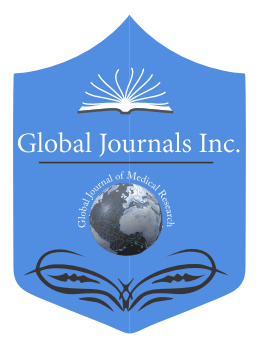

\title{
A Study to Assess the Nutritional Status of Housewives of the Below Poverty Line Families Living in a Slum in the Kidderpore Area of Kolkata, India
}

By Ms. Diksha Sharma \& Dr. Sampa Mitra

All India Institute of Hygiene and Public Health

Abstract- Housewives in the below poverty line (BPL) families are at a high risk of suffering from malnutrition, because of poverty, and the fact that they often give priority to the nutritional needs of other family members, neglecting their own. This study has attempted to assess the nutritional status of housewives of the BPL families living in a slum in the Kidderpore area of Kolkata (India), by employing binomial tests at $5 \%$ level of significance, and using three indicators viz., body mass index or BMI, presence of angular stomatitis, and presence of pallor, and one predisposing factor viz., frequency of consumption of green leafy vegetables. Chi-square tests at $5 \%$ level of significance have been utilized to check the associations between the frequency of consumption of green leafy vegetables and the occurrence of pallor, and between the physiological condition and the presence of pallor, among the housewives. The results show that a significant number of housewives of the concerned slum are neither suffering from, nor predisposed to, malnutrition, so far as the aforesaid indicators and predisposing factor are concerned, and that there is a significant association between the frequency of consumption of green leafy vegetables and the occurrence of pallor, whereby the likelihood of the latter decreases as the former increases. The outcomes also show that there is a significant relationship between the physiological condition and the presence of pallor, whereby the pregnant/lactating housewives (these women have higher nutritional needs) are more susceptible to pallor than the non-pregnant and the non-lactating ones.

Keywords: nutritional status, housewife, BPL, slum, BMI, angular stomatitis, pallor, green leafy vegetables, physiological condition, binomial test, chi-square test.

GJMR-L Classification: NLMC Code: QU 145

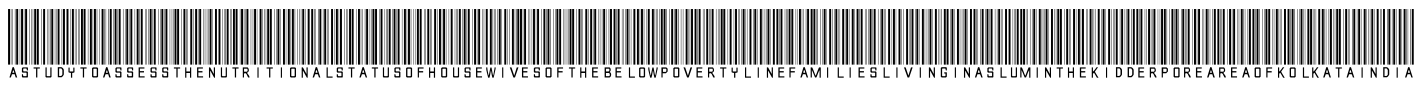

Strictly as per the compliance and regulations of:

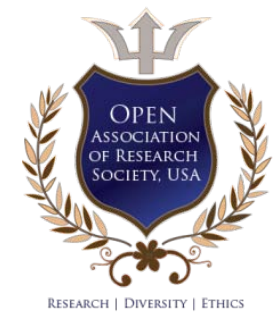

(C) 2020. Ms. Diksha Sharma \& Dr. Sampa Mitra. This is a research/review paper, distributed under the terms of the Creative Commons Attribution-Noncommercial 3.0 Unported License http://creativecommons.org/licenses/by-nc/3.0/), permitting all noncommercial use, distribution, and reproduction in any medium, provided the original work is properly cited. 


\title{
A Study to Assess the Nutritional Status of Housewives of the Below Poverty Line Families Living in a Slum in the Kidderpore Area of Kolkata, India
}

\author{
Ms. Diksha Sharma ${ }^{\alpha} \&$ Dr. Sampa Mitra ${ }^{\sigma}$
}

\begin{abstract}
Housewives in the below poverty line (BPL) families are at a high risk of suffering from malnutrition, because of poverty, and the fact that they often give priority to the nutritional needs of other family members, neglecting their own. This study has attempted to assess the nutritional status of housewives of the BPL families living in a slum in the Kidderpore area of Kolkata (India), by employing binomial tests at $5 \%$ level of significance, and using three indicators viz., body mass index or BMI, presence of angular stomatitis, and presence of pallor, and one predisposing factor viz., frequency of consumption of green leafy vegetables. Chisquare tests at $5 \%$ level of significance have been utilized to check the associations between the frequency of consumption of green leafy vegetables and the occurrence of pallor, and between the physiological condition and the presence of pallor, among the housewives. The results show that a significant number of housewives of the concerned slum are neither suffering from, nor predisposed to, malnutrition, so far as the aforesaid indicators and predisposing factor are concerned, and that there is a significant association between the frequency of consumption of green leafy vegetables and the occurrence of pallor, whereby the likelihood of the latter decreases as the former increases. The outcomes also show that there is a significant relationship between the physiological condition and the presence of pallor, whereby the pregnant/lactating housewives (these women have higher nutritional needs) are more susceptible to pallor than the nonpregnant and the non-lactating ones.
\end{abstract}

Keywords: nutritional status, housewife, BPL, slum, BMI, angular stomatitis, pallor, green leafy vegetables, physiological condition, binomial test, chi-square test.

\section{InTRODUCTION}

n India, monthly per capita consumption expenditure of Rs. 972 in rural areas and Rs. 1407 in urban areas, is considered as the poverty line (Rangarajan, Dev, Sundaram, Vyas, \& Datta, 2014). Therefore, a person spending $<$ Rs. 47 a day in urban areas and $<$ Rs. 32 a day in rural areas, is living below the poverty line in India (Seth Sharma, 2014).

Author a: Student of MSc (Applied Nutrition), Department of Biochemistry and Nutrition, All India Institute of Hygiene and Public Health (AllH \& PH), Kolkata, India.

Author б: Corresponding Author; Director Professor, Department of Epidemiology, All India Institute of Hygiene and Public Health (AllH \& PH), Kolkata, India.e-mail: sampamitra2003@yahoo.co.in
In urban areas, generally, the slum-dwelling people are living below the poverty line. A slum is a densely populated area (usually in a city) of substandard housing, unsanitary conditions and social disorganization (The Editors of Encyclopaedia Britannica, 2020).

A housewife is a woman (usually married) managing a household (Thompson, 1996). In other words, a housewife's main occupation is running or managing the home, caring for her children and other family members, cooking and storing food, buying necessary goods for the family etc.

Housewives in the below poverty line (BPL) families are at a high risk of suffering from malnutrition, because of poverty, and the fact that they often give priority to the nutritional needs of their children, husband and other family members, neglecting their own. Hence, it is necessary to know, whether the housewives of the BPL families are suffering from malnutrition, and, if so, to what extent.

So, this study has attempted to assess the nutritional status of housewives of the BPL families living in a slum in the Kidderpore area of Kolkata (India).

It is a cross-sectional study conducted on 96 housewives, in the age-group of 20-60 years (belonging to the BPL families living in a slum of the Kidderpore region of Kolkata); these 96 housewives had been selected using simple random sampling technique. The study period is 6 months, and the study was conducted between March 2018 and September 2018. During the study, house-to-house visit was undertaken with a predesigned and pretested questionnaire (for extracting relevant information) and suitable measuring instruments (for recording weight and height); besides, important physical signs and symptoms (indicating nutritional deficiency), if any, were also noted.

The sample size (n) was calculated using equation (1):

$$
\mathrm{n}=\frac{\mathrm{z}^{2} \mathrm{p} 1(1-\mathrm{p} 1)}{\mathrm{d}^{2}}
$$

where,

$z=$ level of confidence as per the standard normal distribution $=1.96$ (for 95\% level of confidence), 
p1 = estimated proportion of the population that represents the relevant characteristic i.e., malnutrition $=$ 0.5 (since p1 is unknown, it is taken as 0.5),

$\mathrm{d}=$ tolerated margin of error $=0.1$ (for $10 \%$ allowable error).

After calculation, one gets, $n=96.04 \simeq 96$.

To understand the nutritional status of housewives, three indicators viz., body mass index or BMl (the weight in kilograms divided by the square of the height in metres), presence of angular stomatitis (inflammation of one or both corners of the mouth due to vitamin $B_{2}$ deficiency and other reasons), and presence of pallor (pale colouring of the skin, generally of the face and the palms, due to anaemia and other reasons), and one predisposing factor viz., frequency of consumption of green leafy vegetables (green leafy vegetables constitute an important source of nutrition), were considered. For studying the nutritional status with the help of the aforesaid indicators and predisposing factor, the binomial tests were done at $5 \%$ level of significance. The formula for calculating the $p$-value (p11) is given by equation (2):

$$
\mathrm{p} 11=2 \frac{\mathrm{n} !}{(\mathrm{n}-\mathrm{X}) ! \mathrm{X} !} \mathrm{p}^{\mathrm{X}} \mathrm{q}^{(\mathrm{n}-\mathrm{X})}
$$

where,

$\mathrm{n}=$ total number of housewives $=$ sample size $=96$,

$X=n / 2=48$,

$\mathrm{p}=$ proportion of cases corresponding to the first variable pertaining to an indicator (the value in the first column in any one of tables- 1 to 4 ),

$\mathrm{q}=$ proportion of cases corresponding to the second variable pertaining to the same indicator (the value in the second column in the same table).

If $\mathrm{p} 11<0.05$, for a criterion, then one can draw an inference about the nutritional status of a significant number of housewives, using the relevant indicator or factor; otherwise, no such inference can be drawn.

To ascertain whether there is a significant association between the frequency of consumption of green leafy vegetables and the occurrence of pallor among the housewives, and also whether there is a significant relation between the physiological condition (i.e., whether a housewife is pregnant/lactating or not) and the presence of pallor among the housewives, the chi-square tests were done at $5 \%$ level of significance. The formula for chi-square $\left(\chi^{2}\right)$ is given by equation (3):

$$
\chi^{2}=\sum \frac{(0-E)^{2}}{E}
$$

where,

$\mathrm{O}=$ each observed value in any one of tables -5 and 6 , $\mathrm{E}=$ each expected value in the same table $=$ (row total $X$ column total / grand total) corresponding to each value in that table, p2 = p-value (calculated using relevant software system) corresponding to the chi-square value with 1 degree of freedom.

If p2 $<0.05$, then it can be concluded that the relevant association is significant; otherwise, it (i.e., the pertinent association) is not significant.

It may be noted here that the nutritional needs of a pregnant/lactating woman is higher than those of a non-pregnant and non-lactating one.

Before undertaking this work, a brief literature survey was conducted, but no study related to the nutritional status of housewives of BPL families of Kidder pore area, was found.

\section{Methodology}

The outline of the method adopted in this work, is shown in figure-1.

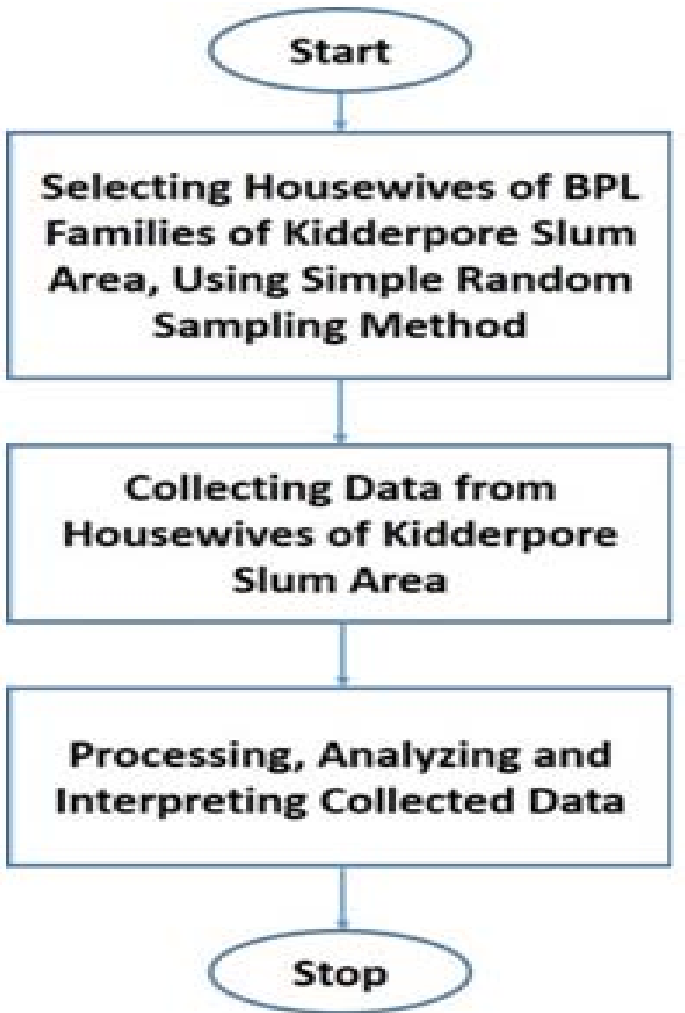

Figure 1: Flowchart depicting the outline of the method

\section{ili. Results And Discussions}

Table-1 categorizes the housewives into two classes according to BMI.

Table 1: Classification of housewives according to BMI

\begin{tabular}{|c|c|c|}
\hline $\begin{array}{c}\text { Normal/overweight } \\
(\mathrm{BMI}>=18.00)\end{array}$ & $\begin{array}{c}\text { Underweight } \\
(\mathrm{BMl}<18.00)\end{array}$ & Total \\
\hline 57 & 39 & 96 \\
\hline
\end{tabular}

According to table-1, 57 housewives are either normal or overweight. Here, the p-value for the binomial test is, $\mathrm{p} 11=0.0292<0.05$. Thus, a significant number 
of the housewives are not suffering from malnutrition, so far as the BMI is concerned.

In table-2, the housewives are classified into two groups according to lip condition.

Table 2: Categorization of housewives according to lip condition

\begin{tabular}{|c|c|c|}
\hline $\begin{array}{c}\text { Presence of angular } \\
\text { stomatitis }\end{array}$ & Normal lip & Total \\
\hline 24 & 72 & 96 \\
\hline
\end{tabular}

As per table-2, 72 housewives have normal lip. Here, the $\mathrm{p}$-value for the binomial test is, $\mathrm{p} 11=1.6355$ $X 10^{-7}<0.05$. Therefore, a significant number of housewives are not suffering from malnutrition, so far as the occurrence of angular stomatitis is concerned.

In table-3, the housewives are grouped into two categories according to skin colour.

Table 3: Classification of housewives according to skin colour

\begin{tabular}{|c|c|c|}
\hline $\begin{array}{c}\text { Presence of } \\
\text { pallor }\end{array}$ & $\begin{array}{c}\text { No presence } \\
\text { of pallor }\end{array}$ & Total \\
\hline 38 & 58 & 96 \\
\hline
\end{tabular}

In table-3, 58 housewives do not have pallor. Here, the p-value for the binomial test is, $\mathrm{p} 11=0.0193$ $<0.05$. Hence, a significant number of housewives are not suffering from malnutrition, so far as the occurrence of pallor is concerned.

Table-4 categorizes the housewives into two groups according to frequency of consumption of green leafy vegetables.

Table 4: Grouping of housewives according to frequency of consumption of green leafy vegetables

\begin{tabular}{|c|c|c|}
\hline $\begin{array}{c}\text { 0-3 days in a } \\
\text { week }\end{array}$ & $\begin{array}{c}>\text { 3 days in a } \\
\text { week }\end{array}$ & Total \\
\hline 14 & 82 & 96 \\
\hline
\end{tabular}

Table-4 shows that 82 housewives consume green leafy vegetables for more than 3 days in a week. Here, the p-value for the binomial test is, $\mathrm{p} 11=4.8793$ $X 10^{-16}<0.05$. So, a significant number of housewives are not predisposed to malnutrition, so far as the frequency of consumption of green leafy vegetables is concerned.

Table-5 shows the relation between the frequency of consumption of green leafy vegetables and the presence of pallor, among the housewives.

Table 5: Association between the frequency of consumption of green leafy vegetables and the presence of pallor, among the housewives

\begin{tabular}{|c|c|c|c|}
\hline $\begin{array}{c}\text { Frequency of consumption } \\
\text { of green leafy vegetables }\end{array}$ & Presence of pallor & No presence of pallor & Total \\
\hline $0-3$ days in a week & 12 & 2 & 14 \\
\hline$>3$ days in a week & 26 & 56 & 82 \\
\hline Total & 38 & 58 & 96 \\
\hline
\end{tabular}

As per table-5, out of the 14 housewives who consume green leafy vegetables for not more than 3 days in a week, 12 have pallor, and among the 82 housewives who consume green leafy vegetables for more than 3 days in a week, 56 do not have pallor. Here, the $\mathrm{p}$-value for chi-square test is, p2 $=1.3598 \times 10^{4}<$ 0.05 . So, there is a significant relation between the frequency of consumption of green leafy vegetables and the presence of pallor, among the housewives, and more is the frequency of consumption, less is the chance of occurrence of pallor.

Table-6 shows the association between physiological condition and presence of pallor, among the housewives.

Table 6: Relation between physiological condition and presence of pallor, among the housewives

\begin{tabular}{|c|c|c|c|}
\hline Physiological condition & Presence of pallor & No presence of pallor & Total \\
\hline Pregnant/lactating housewife & 26 & 7 & 33 \\
\hline $\begin{array}{c}\text { Non-pregnant and non- } \\
\text { lactating housewife }\end{array}$ & 12 & 51 & 63 \\
\hline Total & 38 & 58 & 96 \\
\hline
\end{tabular}

According to table-6, out of the 33 pregnant/lactating housewives, 26 have pallor, and among the 63 non-pregnant and non-lactating housewives, 51 do not have pallor. Here, the p-value for chi-square test is, $\mathrm{p} 2=1.3142 \times 10^{-8}<0.05$. Hence, there is a significant association between the physiological condition and the presence of pallor, among the housewives, and the chance of occurrence of pallor is more among the pregnant/lactating housewives than among the non-pregnant and nonlactating ones.

Thus, the results of the binomial tests and the chi-square tests indicate that:

- A significant number of housewives of the concerned slum of the Kidderpore region, are not 
suffering from malnutrition, so far as the three indicators viz., BMl, presence of angular stomatitis, and presence of pallor, are concerned; besides, a significant number of housewives are also not predisposed to malnutrition, as indicated by the predisposing factor viz., frequency of consumption of green leafy vegetables. This is probably because, Kidderpore, being a port area, offers various jobs with not-very-low salaries to the slum-dwellers.

- There is a significant association between the frequency of consumption of green leafy vegetables and the presence of pallor, among the housewives, and the chance of the occurrence of pallor lessens with the increase in the frequency of consumption.

- There is a significant relation between the physiological condition and the occurrence of pallor, among the housewives, and the pregnant/lactating housewives are more susceptible to the occurrence of pallor than the non-pregnant and the nonlactating ones. This is most probably because, the pregnant/lactating housewives of the concerned slum are not getting sufficient nutrition to meet their higher nutritional needs. Therefore, though a significant number of housewives of that slum are not suffering from malnutrition, this is not the case for most of the pregnant/lactating women among them.

\section{Conclusions}

This study shows that a significant number of housewives of the concerned slum of the Kidderpore region, are not suffering from malnutrition, so far as the three indicators viz., BMl, presence of angular stomatitis, and presence of pallor, are concerned, and that a significant number of housewives are also not predisposed to malnutrition, as indicated by the predisposing factor viz., frequency of consumption of green leafy vegetables. This is an interesting result because, in India, the slum-dwelling people are generally considered to be belonging to the BPL category, and the housewives of BPL families normally suffer from malnutrition. A possible explanation for this anomalous outcome is that, since Kidderpore is a port area, a considerable number of slum-dwellers of this region are employed with not-very-low salaries. However, to ascertain this theory, a thorough study on the occupations and incomes of the people of the concerned slum, should be undertaken. Also, other indicators associated with the nutritional status of the housewives of that slum, should be investigated. Besides, nutritional studies should be conducted on the housewives living in other nearby slums (if any) of this region, to see whether similar results are obtained.

This work also shows that there is a significant association between the frequency of consumption of green leafy vegetables and the presence of pallor, among the housewives, and that the chance of the occurrence of pallor lessens with the increase in the frequency of consumption. This is an expected result.

Another outcome of the study is that there is a significant relation between the physiological condition and the occurrence of pallor, among the housewives, and that the pregnant/lactating housewives are more susceptible to the occurrence of pallor than the nonpregnant and the non-lactating ones. This shows that the nutritional levels of the housewives of the concerned slum are not sufficient to meet the higher nutritional needs of most of the pregnant/lactating women among them. To address this problem, the government can take appropriate measures to provide financial assistance to the pregnant/lactating housewives of BPL families, and to educate the members (both male and female) of BPL families regarding the higher nutritional needs of the pregnant/lactating women.

\section{ACKNOWLEDGEMENTS}

The authors would like to acknowledge their indebtedness to the housewives of the BPL families of Kidderpore area, for their cooperation in the data collection process.

\section{References Références Referencias}

1. Rangarajan, C., Dev, S. M., Sundaram, K., Vyas, M., \& Datta, K. L. (2014). Report of the Expert Group to Review the Methodology for Measurement of Poverty.

2. Seth Sharma, Y. (2014). India Has 100 Million More Poor: C Rangarajan Committee. The Economic Times. Retrieved from https://economictimes.in diatimes.com/news/economy/indicators/india-has-10 0-million-more-poor-c-rangarajan-committee/articles how/37912837.cms

3. The Editors of Encyclopaedia Britannica. (2020). Slum. In Encyclopaedia Britannica. Retrieved from https://www.britannica.com/topic/slum

4. Thompson, D. (Ed.). (1996). Housewife. In The Concise Oxford Dictionary (p. 659). 